\title{
Corrosion Behavior of 7075-T6 Aluminum Alloy in the Presence of Aspergillus Niger
}

\author{
Qi Fan ${ }^{1}$, Lei Fu ${ }^{1,3, *}$, Li Lin $^{2,3,4, * *}$, Sheng Lai ${ }^{1}$, Xin jie Huang ${ }^{1}$, Yingqian Zhang ${ }^{5}$, Yunrong Luo ${ }^{1}$, \\ Xiulan $\mathrm{Li}^{1}$, HaiZhou Zhang ${ }^{6}$ \\ ${ }^{1}$ School of Mechanical Engineering, Sichuan University of Science \& Engineering \\ ${ }^{2}$ Key Laboratory of Sichuan Colleges on Industry Process Equipment and Control Engineering \\ ${ }^{3}$ Key Laboratory of Material Corrosion and Protection of Sichuan Province \\ ${ }^{4}$ College of Materials and Chemistry and Chemical Engineering, Chengdu University of Technology \\ ${ }^{5}$ School of Civil Engineering,Sichuan University of Science \& Engineering \\ ${ }^{6}$ Faculty of Intelligence Manufacturing, YiBin University \\ *E-mail: kunmingfulei@126.com; 1312019411@qq.com
}

Received: 16 May 2021 / Accepted: 8 July 2021 / Published: 10 August 2021

Aspergillus niger is a fungus that can promote the corrosion of aluminum alloys. In this paper, the corrosion behavior of 7075-T6 aluminum alloy in the presence of Aspergillus niger was investigated with the corrosion weight-loss method, electrochemical tests, scanning electron microscopy (SEM), and inductively coupled plasma optical emission spectrometry (ICP-OES). The results showed that Aspergillus niger greatly promoted the corrosion behavior of 7075-T6 aluminum alloy, and the corrosion rate was 6-12 times that of the sterile system. The electrochemical results showed that the corrosion process of the aluminum alloy was promoted by Aspergillus niger, and a large number of corrosion pits appeared on the surface with increasing exposure time. The research results confirmed that Aspergillus niger can significantly promote the corrosion of aluminum alloys.

Keywords: Aspergillus niger; Aluminum alloy; Microbiologically influenced corrosion; Electrochemical characteristics

\section{FULL TEXT}

(C) 2021 The Authors. Published by ESG (www.electrochemsci.org). This article is an open access article distributed under the terms and conditions of the Creative Commons Attribution license (http://creativecommons.org/licenses/by/4.0/). 